\title{
DISCURSO E SOCIEDADE NA AULA DE INGLÊS COMO LÍNGUA ADICIONAL: PROPOSTA DE ENSINO BASEADO EM CONTEÚDO SOB A PERSPECTIVA EDUCATIVA DE PROJETOS DE TRABALHO
}

\author{
Désirée Motta-Roth ${ }^{1^{*}}$ \\ ${ }^{1}$ Universidade Federal de Santa Maria, Santa Maria, RS, Brasil \\ Helena Vitalina Selbach ${ }^{2 * *}$ \\ ${ }^{2}$ Universidade Federal de Pelotas, Pelotas, RS, Brasil
}

\begin{abstract}
Resumo
Apresentamos uma proposta de ensino de Inglês como Língua Adicional, assumindo os conceitos de discurso (linguagem como prática social em gêneros discursivos) como constitutivo da vida social e, portanto, essencial a questões que envolvem a experiência humana. Associamos conceitos da Perspectiva educativa de projetos de trabalho (HERNÁNDEZ, 2014) e do Ensino baseado em conteúdo (LYSTER, 2018), exemplificando nossa discussão com um projeto interdisciplinar, como possível abordagem de referência para uma variedade de propostas pedagógicas situadas em diferentes contextos de ensino. Tentamos expor os desafios e as vantagens da apropriação do conceito de gênero discursivo, considerando discussões no campo da Linguística Aplicada e possibilidades atuais para a educação linguística.
\end{abstract}

\footnotetext{
"Professora Titular de Inglês, Linguística Aplicada, Análise Crítica do Discurso e Teoria de Gêneros Discursivos do Curso de Graduação e do Programa de Pós-Graduação em Letras, Universidade Federal de Santa Maria, onde leciona desde 1984 e, desde 1998, atua como coordenadora científica do LABLER-Laboratório de Pesquisa e Ensino de Leitura e Redação. É Mestre em Linguística Aplicada pela Pontifícia Universidade Católica do Rio Grande do Sul (1990), Doutora em Letras (Inglês) pela Universidade Federal de Santa Catarina (1995), com estágios de Pós-Doutorado no English Language Institute, Universidade de Michigan (Set/2002 a Jan/2003) e no LAEL-Programa de Pós-Graduação em Linguística Aplicada, Pontifícia Universidade Católica de São Paulo (Mar a Set/2009). Desde 1998, atua como Pesquisadora do CNPq e do Grupo de Pesquisa/CNPq "Linguagem como Prática Social” (Ref. UFSM.0043). Desenvolve pesquisa, ensino e extensão na área de Linguística Aplicada sobre teoria, análise e ensino de práticas discursivas escritas em contextos específicos, teoria e análise crítica de gêneros discursivos acadêmicos e ensino e aprendizagem de línguas (inglês e português). E-mail: mottaroth@ gmail.com ORCID: http://orcid.org/0000-0002-7432-5532.

"* Professora adjunta no Centro de Letras e Comunicação da Universidade Federal de Pelotas (UFPel). Atuou na Universidade Federal de Santa Maria (UFSM) e na Universidade Franciscana (UFN). É Doutora em Letras (Estudos Linguísticos) pela UFSM (2018), Mestre em Linguística Aplicada pela Universidade Federal do Rio Grande do Sul (2014), Bacharel em Letras (Português-Inglês) pela mesma universidade (2000) e Licenciada em Letras (Português-Inglês) pela UFN (2017). Colaborou, durante seu doutoramento, com o projeto "Letramento acadêmico/científico e participação periférica legítima em comunidades na produção de conhecimento" (MOTTA-ROTH, 2014-2018) da linha de pesquisa "Linguagem no contexto social" do Programa de PósGraduação em Letras da UFSM, associada ao Grupo de Pesquisa/CNPq "Linguagem como prática social". Atualmente, atua como Coordenadora Adjunta da Área de Português para Estrangeiros do Programa Idiomas sem Fronteiras (IsF/UFPel) e do Programa Português Para Estrangeiros (PPE) da UFPel. Suas áreas de interesse, inscritas na Linguística Aplicada, voltam-se a práticas de letramento, ensino e aprendizagem de línguas adicionais e educação inicial e continuada de professores de línguas. E-mail: helenaselbach@gmail.com ORCID: https://orcid.org/0000-0001-9957-8328.
} 
Palavras-chave: Linguística Aplicada; Discurso, Educação e Sociedade; Gêneros discursivos; Ensino e Aprendizagem de Línguas; Inglês como Língua Adicional

\title{
DISCOURSE AND SOCIETY IN THE ENGLISH AS ADDITIONAL \\ LANGUAGE CLASSROOM: SUSTAINED CONTENT-BASED TEACHING APPROACH GROUNDED ON THE EDUCATIONAL PERSPECTIVE OF WORK PROJECTS
}

\begin{abstract}
We present a teaching proposal for English as Additional Language, adopting the concepts of discourse (language as social practice in discourse genres) as constitutive of social life and, thus, essential to issues pertaining to the human experience. We associate concepts from the Educational perspective of work projects (HERNÁNDEZ, 2014) and from the Sustained content-based teaching approach (LYSTER, 2018), exemplifying our discussion with an interdisciplinary project, proposed as a possible approach from which a variety of situated pedagogical proposals can depart to attend to different teaching contexts. We indicate challenges and advantages of the appropriation of the concept of discourse genre, considering present discussions in the field of Applied Linguistics and possibilities for language education.

Keywords: Applied Linguistics; Discourse, Education and Society; Discourse Genres; Language Teaching and Learning; English as an Additional Language
\end{abstract}




\section{Introdução $^{1}$}

A publicação dos Parâmetros Curriculares Nacionais (PCN) (BRASIL, 1998) influenciou fortemente o campo da Linguística Aplicada (LA) e demarcou o conceito de gênero como eixo central nos debates sobre ensino de linguagem e formação de professoras ${ }^{2}$ ao longo das últimas décadas. Tais debates ensejaram a convivência com diferentes teorias de gêneros discursivos (por exemplo, MEURER; BONINI; MOTTA-ROTH, 2005), como o Interacionismo Sociodiscursivo (BRONCKART, 1999), a Sociorretórica (BAZERMAN, 2009) ou a Linguística Sistêmico-Funcional (MARTIN, 1999).

Neste artigo, primeiramente explicitamos o conceito teórico de gênero discursivo como norteador de nossa discussão. Em seguida, apresentamos propostas de Ensino baseado em conteúdo (LYSTER, 2018) e da Perspectiva Educativa de Projetos de Trabalho ${ }^{3}$ ou PEPT (HERNÁNDEZ, 1998; 2014; BARBOSA, 2004), duas perspectivas teóricas conhecidas na LA. Por fim, debatemos o desenho de um projeto interdisciplinar de Inglês como Língua Adicional (ILA), ${ }^{4}$ ilustrando uma possível abordagem para que cada professora possa situar sua tarefa de ensino, fugindo de fórmulas gerais. Oferecemos nossa contribuição para discussões no campo da LA sobre educação linguística e para o debate acadêmico na área de ILA na medida em que explicitamos o modo como conceitos teóricos relativos ao estudo da linguagem, como Discurso, Gênero Discursivo e Planos Comunicativos da Linguagem, podem ser integrados a atividades sociais e práticas pedagógicas em um projeto pedagógico interdisciplinar. Para tanto, discutiremos maneiras para: a) Identificar necessidades/problemas da turma e da comunidade escolar específica para promover uma educação crítica; e b) Desenhar um projeto para o estudo dessas necessidades, com objetivos a serem alcançados e possíveis ações para interferir beneficamente na comunidade (SCHERER et al., 2014, p. 99). Tentamos expor desafios e vantagens da apropriação do conceito de gênero discursivo, considerando o fazer pedagógico e as discussões no campo da LA, sem perder de vista possibilidades para a educação linguística no século 21 .

Assumimos a PEPT por ser esta "uma perspectiva educativa que não segue o que é hegemônico e dominante na educação" (HERNÁNDEZ, 2014, p. 66) e que encoraja a aprendizagem situada em contextos específicos, articulando conhecimentos de diferentes naturezas (diferentes disciplinas, conhecimentos teóricos e práticos, escolares e domésticos, míticos e do senso comum, por exemplo), considerando:

- a necessidade de examinarmos o conjunto das matérias escolares como pontos de referência para uma proposta de projeto interdisciplinar ${ }^{5}$, que ajuda estudantes a estabelecer relações entre as diferentes matérias a partir do que se faz em sala de aula (HERNÁNDEZ, 1998, p. 18);

- a inexistência de uma fórmula única de ensino e de aprendizagem a ser replicada em qualquer contexto; 
- a importância de a professora ser "autora" de seus próprios planos de ensino como uma "intelectual transformadora" (GIROUX, 1997, p. 28-29), que, em vez de apenas reproduzir informações acerca de conteúdos curriculares, constrói, para si e para estudantes, um espaço de investigação (KINCHELOE, 2003), de elaboração de conceitos, de recontextualização da aprendizagem, de experimentação e de reflexão sobre essas etapas do processo de construção de conhecimento.

Também adotamos a perspectiva de Ensino baseado em conteúdo (Sustained content-based approach ou Content-based instruction) (PALLY, 1999; PALLY et al., 2002), porque propõe a busca de um tema-problema que perpassa várias disciplinas do currículo escolar, de modo que práticas discursivas de produção, distribuição e consumo de textos em ILA sejam constitutivas de atividades de construção de conhecimento e de interferência no mundo.

Exemplificamos nosso debate por meio do material didático (SCHERER et al., 2014) desenvolvido por nós para a oficina ministrada pela primeira autora deste $\operatorname{artigo}^{6}$ para formação continuada de professoras de ILA. Do mesmo modo que naquela oficina, nossa meta é debater o conceito de linguagem como prática social, tomando gênero discursivo como textualização da experiência humana:

Partiremos do pressuposto de que a textualização da experiência humana envolve a língua em uso: a mobilização, ao mesmo tempo, de léxico-gramática, texto, registro, gênero e discurso, em função da interdependência entre esses vários planos. Do mesmo modo, a produção de sentido implica a percepção das relações entre texto e contexto, da conexão entre experiência individual, experiências sociais e condições sócio-históricas de produção, distribuição e consumo dos textos na sociedade (Freire, [1982] 2000; Fairclough, 1989 apud MOTTA-ROTH, 2011).

Em última instância, visamos encorajar professoras a desenvolverem planos de ensino de ILA de sua própria autoria, a partir da investigação das "características, peculiaridades, necessidades e interesses locais de cada escola e de cada comunidade" (SCHERER et al., 2014, p. 10).

\section{Gêneros discursivos e os vários planos da linguagem}

Os PCN originalmente propuseram Temas Transversais importantes - Ética, Saúde, Meio Ambiente, Orientação Sexual, Pluralidade Cultural (BRASIL, 1998) - para a elaboração de um projeto pertinente a problemas e necessidades da comunidade escolar. Podemos pensar nesses temas como foco de discursos circulantes na sociedade, daquilo que Gee (1999, p. 13) chama de "Conversações" em voga na sociedade:

[...] assuntos duradouros e importantes que têm sido o foco de uma variedade de diferentes textos e interações (em diferentes linguagens sociais e 
discursos), que atravessam um significativo período de tempo e um amplo conjunto de instituições (tradução nossa).

Essas Conversações surgem em conexão com as práticas sociais. Os discursos formulam determinados pontos de vista sobre temas que circulam nas Conversações que originam e, ao mesmo tempo, resultam de interações e fatos sociais (FAIRCLOUGH, 1992; 2003) em uma relação dialética. Enquanto discursos se materializam nos textos circulantes, produzidos, distribuídos e consumidos em sociedade, essas Conversações ocorrem sempre em situações localizadas no tempo e no espaço em sistemas de atividades sociais. Assim, os textos assumem papel constitutivo nas atividades sociais, manifestando-se como gêneros discursivos - a dimensão linguístico-semiótica da experiência humana. Tomamos como pressuposto que toda comunicação é ideologicamente investida como discurso e sempre acontece em alguma atividade social, assumindo, portanto, a forma e a função de gêneros discursivos específicos (FAIRCLOUGH, 1992; 2003).

Nos tempos atuais, por exemplo, as discussões sobre a convivência com as diferenças têm acirrado, por vezes, o que se pode chamar de discurso racista: "avaliações absolutas e generalizantes das diferenças que são vantajosas a quem acusa e perniciosa à vítima (Reisigl and Wodak, 2001, p. 5)” (CALDAS-COULTHARD, 2003, p. 287).

Nesses termos, o discurso racista bem como as identidades e relações sociais associadas a ele podem ser atualizados em gêneros discursivos tão variados como uma placa de sinalização (Figura 1) ou um anúncio de emprego (Figura 2).

Figura 1 - Placa de sinalização oficial "sala de espera apenas para negros"

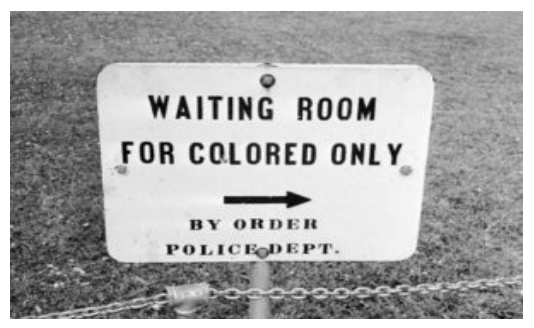

Fonte: Kenney (2016)

A instância ideológica do discurso racista se atualiza nesses dois gêneros discursivos diferentes constitutivos de duas atividades sociais - regulamentar a circulação das pessoas, de acordo com as leis de segregação racial especialmente observadas no sul dos Estados Unidos (Figura 1) (KENNEY, 2016) e anunciar vaga de emprego a partir de uma ótica racista (Figura 2). Ambas, porém, funcionam a partir de um mesmo ponto de vista, posto que naturalizam (fazem parecer natural aquilo que é, de fato, invenção cultural) práticas de exclusão por raça na linguagem. 
Figura 2 - Anúncio de emprego "Apenas mulheres brancas cristãs"

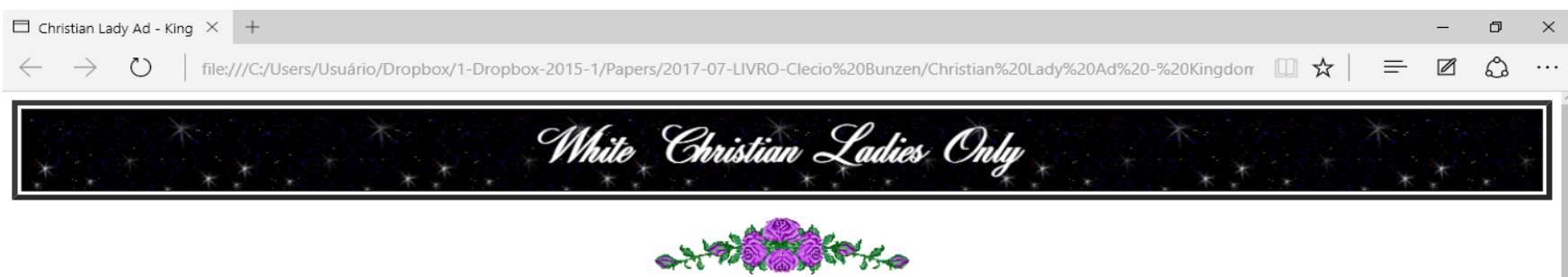

WE NEED A QUALITY DEDICATED CHRISTIAN WHITE LADY to be part of this Christian Identity ministry. Varied responsibilities, preferably including secretarial skills. Desire a believer who is intelligent, reliable, competent, pleasant, neat, and careful in details. An important, interesting, fulfilling life on rural acreage located in the beautiful Ozark Mountains. Must be racially pure, honest and of high moral character. Should have genuine sweet, gentle, feminine mannerisms and be easy to get along with. Government, Jewish, or other agents DO NOT qualify! Position should be regarded as a calling in Christian service, not just another job. Room, board, and spending money will be provided.

If you think this opportunity may be right for you, send your address, phone number, a recent photograph, and a description of yourself to this ministry. Girls under 18 need to have their parents' permission. Ladies of our race from Europe and other countries abroad, who qualify, are welcome to apply.

Send all mail to:

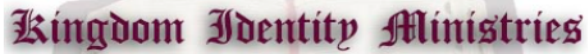 \\ P.O. Box 1021 \\ Harrison, Arkansas 72602 \\ (870) 741-1119}

Fonte: https://kingidentity.com/cla-kim.html

Para formular um programa de ensino de ILA pela abordagem PEPT, identificamos, em qualquer ordem - dependendo da necessidade, mas geralmente do plano mais amplo - os pontos de vista (discursos) que desejamos explorar em usos da linguagem específicos a determinadas atividades sociais (gêneros discursivos) e chegando até o plano mais específico dos itens léxico-gramaticais empregados para a comunicação nessas atividades sociais.

No Laboratório de Pesquisa e Ensino de Leitura e Redação (LABLER/ UFSM), trabalhamos com programas de ensino (Figura 3), organizados em planos comunicativos (MOTTA-ROTH, 2008, p. 352), tomando por referência a Linguística Sistêmico-Funcional, exemplificada por trabalhos de Halliday e Matthiessen (2014) e de Halliday e Martin (1993) sobre gramática e planificação da linguagem, de Halliday e Hasan ([1985] 1989) e de Martin (1992) sobre textualização, e de Fairclough (2003) sobre práticas discursivas. 
Figura 3 - Programa planificado

\section{Programa planificado}

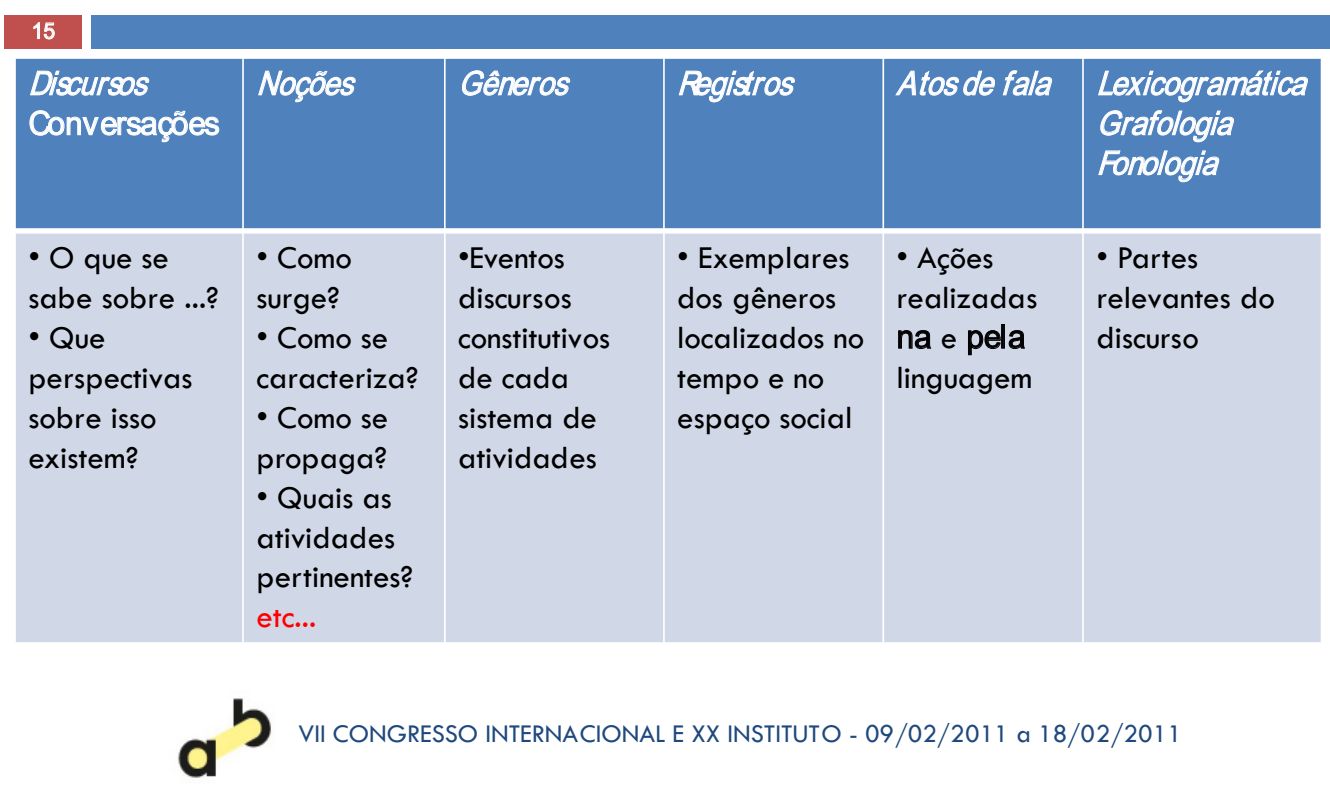

Fonte: Motta-Roth (2011)

Partindo do plano comunicativo mais amplo, do discurso, em direção ao plano mais específico, da léxico-gramática, poderíamos continuar até os planos ainda mais específicos da fonologia e da ortografia, dependendo das necessidades da turma e do currículo. Os planos intermediários do registro e dos atos de fala nos ajudam a fazer escolhas e propiciam a visualização do funcionamento da língua.

O registro situa o exemplar de um gênero discursivo consagrado na cultura, como "notícia de popularização da ciência" (Figura 4), em um determinado ponto do tempo e do espaço (publicada em 2017 na revista Superinteressante). O registro da notícia é caracterizado por linguagem impessoal (o texto não é assinado) e metafórica ("Modo avião", "piloto automático") e difere daquele de uma notícia publicada na revista Ciência Hoje Online, por exemplo, em que aparecem termos técnicos, em tom menos pessoal, escrito na primeira pessoa, assinado pelo jornalista. Registro é a situacionalidade do texto como um exemplar específico de um gênero em relação a três dimensões: 1) a atividade que acontece (popularizar a ciência em uma notícia breve e de linguagem corriqueira na revista Superinteressante); 2) as identidades e a relação entre os participantes do gênero (escritor-jornalista e leitor não são especialistas); e 3) o papel desempenhado pela linguagem naquele contexto de situação (papel constitutivo e não auxiliar, coordenado com a linguagem não verbal da imagem). 
Figura 4 - "Chamada" de notícia de popularização da ciência, publicada no sítio eletrônico da revista Superinteressante

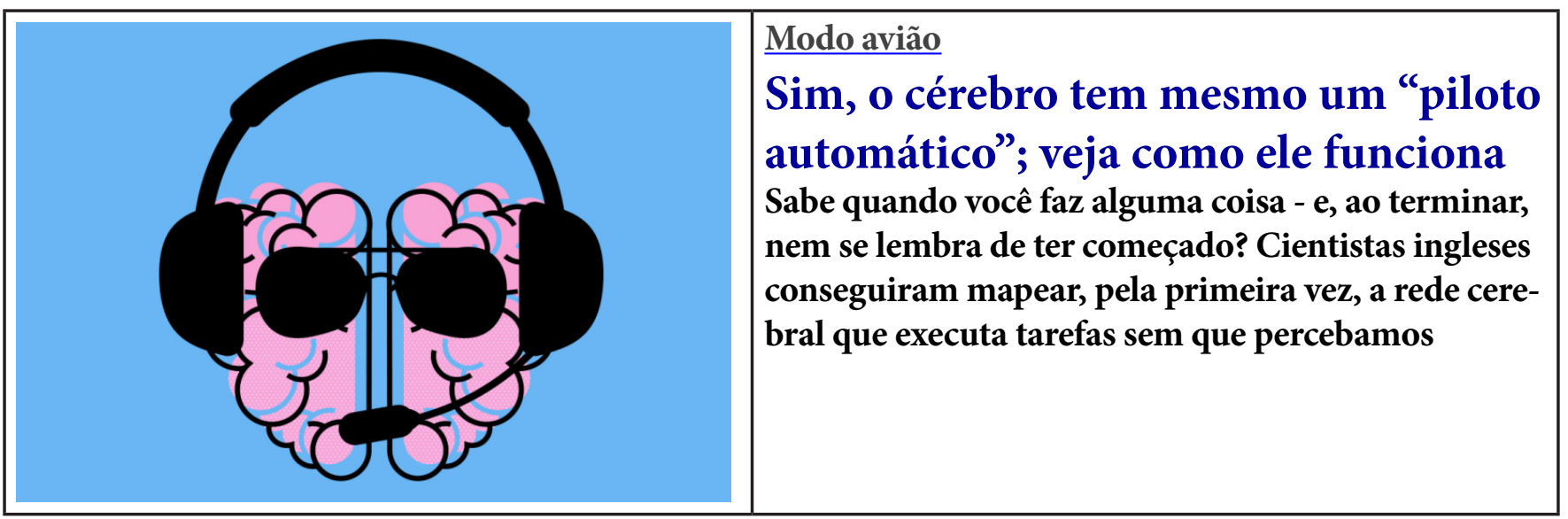

Fonte: https://super.abril.com.br/ciencia/como-funciona-o-piloto-automatico-do-cerebro/

O gênero notícia de popularização da ciência reposiciona a informação do gênero científico original, gerando outras posições de sujeito: se no artigo original havia escritor-especialista/leitor-especialista, na notícia de popularização da revista Ciência Hoje Online, há jornalista-especialista/leitor-não especialista (MOTTA-ROTH, 2010, p. 163).

Atos de fala, como identificar, explicar ou avaliar, são movimentos da interação que fazem avançar o sentido do texto. Na notícia de popularização da ciência, nos seus diversos registros, foram identificados atos de fala que caracterizam o gênero (a atividade social) como citação do discurso de cientistas e explicação de princípios e conceitos científicos (MOTTA-ROTH; LOVATO, 2009, p. 246).

Em relação às partes do discurso ou aos itens léxico-gramaticais que realizam os atos de fala, podem-se vislumbrar itens comumente presentes em programas de ensino de ILA, como reported speech (discurso relatado e uso de aspas para realizar o ato de fala de citação de discurso direto) e os verbos to be e to have (verbos frequentemente utilizados em explicação e definição de conceitos na popularização da ciência, como em "Sim, o cérebro tem mesmo um 'piloto automático"', na Figura 4), ou ainda adjetivos, denotando personality traits para identificação de traços de personalidade desejáveis em anúncios de emprego (como "inteligente, confiável, competente", na Figura 2).

Tal planificação incorpora a ordem metodológica para o estudo da linguagem, sugerida por Volochinov ([1929] 1995, p. 124), que inicia pela identificação do contexto social, passando pelos gêneros, até chegar às formas gramaticais (conforme sintetizado em MOTTA-ROTH, 2008, p. 356): 1) a identificação das formas e dos tipos de interação verbal em conexão com as condições concretas em que se realiza; 2) a identificação dos atos de fala isolados (ou dos gêneros discursivos) em ligação estreita com a interação de que fazem parte; e 3) a análise das formas da língua na sua interpretação linguística habitual. 
Portanto a metodologia sociológica de Volochinov ([1929] 1995) inicia pelo contexto e segue em direção ao texto. $\mathrm{O}$ gênero assim pode ser definido como o evento de linguagem em uso para realizar um determinado objetivo, associado a uma atividade social: lista de supermercado para lembrar mantimentos necessários; anúncio de emprego para preencher funções relevantes ao funcionamento de uma instituição; minuta de contrato para garantir uma relação de compra e venda; ou palestra em escola sobre materiais recicláveis para problematizar o consumo entre os jovens. Pela recorrência do uso da linguagem na enunciação (produção textual), em um dado espaço e tempo de uma situação e o processo histórico-cultural de sua formação, o gênero mantém, em determinados momentos da dinâmica social, algum grau relativo de estabilidade no modo da interação social, na forma, no conteúdo e no estilo da materialidade textual.

\section{Ensino baseado em conteúdo e a PEPT}

A construção e a implementação de um programa de ensino interdisciplinar de ILA que busca melhorias para comunidades escolares pode se beneficiar do Ensino baseado em conteúdo e da PEPT. Esse enfoque implica a elaboração de um currículo integrado, organizado a partir de problemas e temáticas emergentes que podem contribuir para o exercício de ação política da escola e do intelectual docente (KLEIMAN; TINOCO; CENICEROS, 2013, p. 72, com base em HERNÁNDEZ, 2001).

O Ensino de línguas baseado em conteúdo, explica Lyster (2018, p. 1), consiste em: "[...] uma abordagem de ensino na qual um conteúdo não linguístico como geografia, história ou ciências é ensinado a estudantes por meio de uma língua que estão aprendendo como língua adicional” (tradução nossa).

Essa abordagem pedagógica prevê que o curso de ILA acompanhe uma disciplina/um conteúdo/uma temática para além dos conteúdos programáticos de língua, ao longo do período letivo, de modo que as habilidades de linguagem sejam aprendidas e praticadas, com o auxílio da professora, em atividades escritas e orais autênticas para atuação no mundo concreto (PALLY et al., 2002, p. 95). O desenvolvimento do conjunto de letramentos e habilidades linguísticas, por meio do enriquecimento do discurso em sala de aula em termos de conteúdo de ILA e de outra(s) disciplina(s), é o objetivo dessa abordagem pedagógica, de tal modo que cria tanto uma base cognitiva e epistemológica para a aprendizagem de língua quanto uma motivação para a comunicação com objetivos relevantes em contextos de interação (LYSTER, 2018, p. 1-6). Assim, o interesse:

[...] recai sobre a temática, que é complexificada e ampliada com a progressão do projeto. Isso permite o foco na temática formulada em ILA de maneira relevante para os fins do projeto, evitando, exclusivamente, o foco nas estruturas gramaticais e realimentando propostas em outras disciplinas, em função do caráter interdisciplinar do projeto de ILA. Para o desenvolvimento dessa proposta, é necessário o engajamento de estudantes com o projeto de trabalho que, por sua vez, converge para os interesses dos demais participantes, como a comunidade (SCHERER et al., 2014, p. 17-18). 
O Ensino de línguas com base em conteúdo, já adotado em diferentes contextos (MENDONÇA, 2005; EYJÓLFSDÓTTIR, 2011; JUAN-GARAU; SALAZAR-NOGUERA, 2015) relaciona-se à PEPT (HERNÁNDEZ, 1998; 2014; MENEZES; CRUZ, 2007), na medida em que se presta à sustentação contínua de um tópico específico ao longo do desenvolvimento de cada projeto em combinação com uma reflexão centrada nos usos da linguagem em contextos específicos. No Brasil, Mendonça (2005) enfatiza projetos de letramento escolar em que ações efetivas de leitura e produção de textos e de análise linguística articulam-se em torno de um tema central pertinente a diferentes disciplinas escolares, visando ao desenvolvimento de competências, habilidades e conteúdos relevantes. Tais ações são planejadas na forma de atividades didáticas que ensejam a produção coletiva do conhecimento e levam à construção de um produto textual final próprio da turma. Nosso exemplo seria o pôster elaborado pela turma no ensino fundamental ou médio, relatando uma investigação sobre coleta de dejetos e limpeza urbana, para ser apresentado em uma feira de ciências na escola.

Na mesma linha, Kleiman e Moraes (2009, p. 16) ressaltam a importância de todos os professores adotarem uma perspectiva interdisciplinar sobre a educação linguística, porque 1) a construção de conhecimento em todas as disciplinas depende de habilidades de leitura e escrita e 2) a integração curricular "traz as perspectivas, conhecimento, e a habilidade de coletar dados de todas as disciplinas" (KLEIMAN; MORAES, 2009, p. 27). As autoras mencionam também a importância de a proposta pedagógica de projeto nascer das condições locais da comunidade para atender suas necessidades (KLEIMAN; MORAES, 2009, p. 18).

Um projeto, por sua vez, abre múltiplas possibilidades de respostas/abordagens a problemas que dizem respeito às comunidades escolares por meio da construção conjunta (situada, sob forma de autoria singular ou de grupo) de resolução/ões (BARBOSA, 2004). Essa proposta de trabalho também oportuniza:

[...] momentos de autonomia e de dependência do grupo; de cooperação do grupo sob uma autoridade mais experiente e também de liberdade; momentos de individualidade e de sociabilidade; de interesse e de esforço [...] como fatores que expressam a complexidade do fato educativo (BARBOSA, 2004, p. 9).

Por estar fundada na prática de investigação, a PEPT enseja a reflexão e o aprofundamento do estudo sobre um mesmo fenômeno a partir de diferentes disciplinas (DEWEY, 1967; HERNÁNDEZ, 1998) e encoraja o estabelecimento de relações entre a escola e as práticas sociais da comunidade das quais o estudante participa (como a família, organizações religiosas, comerciais e sindicatos, por exemplo):

Para aprender é preciso ir construindo andaimes e relações com sentido. Alguns estão nas disciplinas ou, em outros casos, em campos do saber que não se restringem aos limites disciplinares. Também se constroem a partir do diálogo, da intuição, do encontro com outros e da experimentação. [...] 
A vida do conhecimento flui a partir do momento em que se descobre e estabelece relações entre fenômenos e experiências. $\mathrm{O}$ intercâmbio com diferentes fontes de experiência possibilita as ancoragens e as relações (HERNÁNDEZ, 2014, p. 67).

A PEPT é uma proposta de ensino pautada na construção da subjetividade, na qual o estudante é instigado a dialogar de maneira crítica com o seu entorno de forma a desenvolver algumas atitudes importantes, como:

- $\quad$ adoção da ideia de que se aprende por meio de participação em atividades sociais concretas (VYGOTSKY, 2001);

- aprendizagem colaborativa (que implica/convoca a atuação conjunta de professoras, estudantes e comunidade) de modo a construir conhecimento intersubjetivamente, no conjunto dos atores sociais (HERNÁNDEZ, 1998; FREIRE, [1974] 2011);

- reflexão crítica sobre o que chamamos de "realidade", por meio do desenvolvimento de habilidades de aprendizagem para toda vida (lifelong learning skills), que pressupõem: a) lidar com o inesperado, b) fazer escolhas informadas, c) desenvolver habilidades precisas de observação, d) construir conhecimento relevante na interação com o mundo e e) guiar-se por valores, convicções e razões próprias, conforme Cots (2006, p. 338, citando VAN LIER, 1996).

Construir propostas de ensino que recontextualizem o conhecimento científico do campo da LA, relacionando teoria e prática pedagógica, constitui-se em desafio especialmente no caso de professoras em formação inicial ou que ainda não passaram por formação continuada em nível de pós-graduação. Essa dificuldade foi vivenciada e problematizada pelo conjunto das participantes da nossa oficina de Parâmetros/Diretrizes curriculares para o ensino de inglês do projeto "Portal WebEnglish". Com o intuito de exemplificar esse processo de recontextualização teórica, apresentamos, na próxima seção, uma possível abordagem à relação entre teoria da linguagem e prática de ensino de ILA, na forma de um plano de ensino/proposta pedagógica de projeto.

\section{Apresentação da proposta pedagógica}

O primeiro pressuposto do projeto interdisciplinar de ILA, a partir da PEPT (HERNÁNDEZ, 1998; 2001; 2014) é de que as recomendações dos documentos oficiais, mas principalmente os princípios teóricos que orientam a visão de linguagem, ensino e aprendizagem da professora, são elementos norteadores da elaboração do projeto (SCHERER et al., 2014). O segundo pressuposto é de que ensinar ILA significa, em última instância, ensinar a analisar os discursos que circulam na sociedade contemporânea (MCCARTHY; CARTER, 1994). Essa aná- 
lise tem como objetivo a ação da professora e de estudantes sobre esses discursos, a fim de causar uma interferência positiva em seu contexto particular, via produção e consumo de textos (MOTTA-ROTH, 2006). Em tempos de internet, ler o mundo e falar de si em ILA constitui-se como oportunidade de estabelecer diálogos com o mundo, por meio dos quais a comunidade escolar assume visibilidade e se dá a conhecer, ao mesmo tempo em que conhece outras realidades para fortalecer identidades e construir conhecimento.

O terceiro pressuposto é a necessidade de estimular o pensamento investigativo e reflexivo (DEWEY, 1933, p. 146-147) como estratégia de conhecimento (HERNÁNDEZ, 1998, p. 24) que questiona representações "únicas" da realidade (HERNÁNDEZ, 1998, p. 27). Ao considerar o entorno escolar e as necessidades da comunidade na elaboração de uma proposta de ensino, professora e estudantes tornam-se protagonistas na seleção e/ou elaboração dos textos relevantes para agir em relação aos problemas sociais que fazem parte do dia a dia de sua comunidade, vinculando o que ensinam/aprendem na escola às preocupações e indagações sobre problemas concretos (HERNÁNDEZ, 1998, p. 25). No atual debate brasileiro sobre violência de gênero, analisar textos da mídia internacional hegemônica sobre o Brasil pode contribuir para a educação linguística crítica na medida em que possibilita questionar a validade dessas representações. Uma boa ideia para projeto envolvendo ILA, filosofia, geografia, história, arte e matemática, pode advir da discussão proposta por Caldas-Coulthard (2003) sobre a necessidade de desnaturalizar representações do Brasil na mídia britânica. A desnaturalização de discursos contemporâneos sobre o Brasil pode embasar, por exemplo, um projeto que discuta o modo como o país está sendo retratado na mídia internacional, em função das políticas públicas adotadas pelo governo atual para o enfrentamento da pandemia de COVID-19 ou para a conservação da floresta amazônica.

Com relação ao papel dos participantes das atividades (professoras e estudantes) durante a realização do projeto, entendemos que lhes cabe oferecer assistência na realização das tarefas na forma de "andaimes" (WOOD; BRUNER; ROSS, 1976) para que cada um realize ações discursivas - tanto como autor quanto como leitor - em práticas sociais situadas em contextos específicos (SCHERER; MOTTA-ROTH, 2015, p. 80). Esses andaimes possibilitam, a cada participante, solucionar um problema ou resolver uma tarefa que estaria além de seus esforços individuais (WOOD; BRUNER; ROSS, 1976), professora e estudantes colaborando para a realização do projeto. Em países como Inglaterra e Eslovênia, estudantes de classes privilegiadas, com acesso doméstico a tecnologias digitais, possuem letramentos digitais significativamente mais avançados em termos de suas ações corriqueiras do que estudantes das classes trabalhadoras (BANAJI; BUCKINGHAM, 2013, p. 49).

Apesar do contato com as tecnologias digitais na vida diária ser também intensa no Brasil, isso não se reflete na integração das Tecnologias de Informação e Comunicação no ensino formal. Reis e Gomes (2014, p. 367) destacam que o Brasil: 
[...] conforme os dados do Ibope NetRatings (2012), é o quinto país que mais acessa a Internet no mundo, com aproximadamente 79,9 milhões de internautas. No entanto, apesar desse panorama demonstrar dados positivos, a inserção de Tecnologias de Informação e Comunicação (TIC) nas práticas docentes ainda é problemática, visto que menos de $50 \%$ das escolas brasileiras têm acesso à Internet (Rodrigues, 2012, p. 1). Diante desses dados, percebemos que a inserção e o uso de TIC nas escolas ainda é inicial; por outro lado, é promissora, pois poderá ocasionar, principalmente, mudanças nas práticas docentes, exigindo dos professores a busca por novos letramentos que possibilitem otimizar recursos disponíveis na Internet em suas atividades pedagógicas.

Nesse cenário de uso intenso das tecnologias de comunicação, alunos e professora podem colaborar com andaimes de conteúdo e de letramentos digitais para o desenvolvimento de uma atividade de ensino que envolva a cultura digital. O papel da professora se destaca ao orientar estudantes a realizar tarefas que estejam além de suas habilidades iniciais de ILA, produzindo sentidos redundantes de diferentes maneiras como repetição, paráfrase, exemplificação, definição, sinonímia, organizadores gráficos/visuais, linguagem corporal (gestos, expressões faciais) e outros tantos elementos paralinguísticos (LYSTER, 2018, p. 7). A literatura (SCHLATTER, 2009; LEFFA; IRALA, 2014) e nossa própria prática pedagógica (MOTTA-ROTH, 2006) têm demonstrado que esse processo encoraja estudantes a desenvolverem competências linguísticas mais ricas do que se tentassem resolver tarefas individualmente e também a dar conta de tarefas das disciplinas cada vez mais complexas apresentadas em ILA, construindo assim conhecimento acadêmico para além do senso comum do cotidiano escolar.

Para a elaboração e subsequente implementação de um projeto pedagógico, em conjunto por professoras e alunos, propomos três etapas cíclicas e não lineares de modo a explorar o conteúdo de ILA e de outra(s) disciplina(s) a partir de perspectivas múltiplas: 1) Sondagem e avaliação de temáticas relevantes para o contexto de ensino e aprendizagem de línguas; 2) Produção do projeto de ensino sobre temáticas relevantes escolhidas pela turma, relacionadas ao contexto; e 3) Avaliação dos resultados, conforme discutiremos a seguir.

\section{Sondagem e avaliação do contexto}

A Sondagem detecta as condições de vida da comunidade escolar (SCHERER et al., 2014) relacionadas à localização, à organização administrativa e pedagógica da escola, às instituições que integram essa comunidade, tais como as associações de bairro, o comércio local, o posto de saúde e os grupos religiosos. Nessa fase, entendemos como fundamental explorar questões ideológicas pertinentes ao ensino de ILA como, por exemplo, qual o papel da língua adicional, na visão de estudantes e demais professoras, para a vida e para a atividade escolar. No Quadro 1, sugerimos algumas perguntas que investigam essas questões contextuais iniciais e que devem ser exploradas em interação entre pares para uma frutífera aprendizagem, tutoria e correção construtiva entre estudantes com auxílio da professora (LYSTER, 2018, p. 8). 
Quadro 1: Perguntas para investigação do contexto escolar

1. Onde sua escola está situada? Descreva o contexto social de sua escola/comunidade/bairro.

2. Quais são as particularidades espaciais do contexto escolar: ruas, construções, edificação da escola, arranjo das salas de aula etc.?

3. Quais são as particularidades organizacionais do contexto escolar: estilo administrativo, perfil da equipe, características do Projeto Político-Pedagógico etc.?

4. Quais são os interesses, a classe social e a idade de estudantes, pais e mães, professoras e funcionários de seu contexto escolar?

5. Como sua disciplina é vista pelos estudantes? Por colegas? Pela administração escolar?

6. Qual situação em sua comunidade escolar parece mais adequada ou disponível para o desenvolvimento de um projeto de aprendizagem?

7. Qual(is) prática(s) social(is) é(são) considerada(s) mais relevante(s)/significativa(s) no cotidiano de estudantes? O que você sabe sobre essa(s) prática(s) social(is)? Como podemos saber mais sobre ela $(s)$ ?

8. Que tema(s) parece(m) mais relevante(s) para ser(em) discutido(s)/investigado(s)/ aprendido(s) em aulas de ILA em um projeto de aprendizagem? Por quê? Quais temas/problemas podem/devem ser abordados? Por quê?

9. Quais conceitos e princípios seriam relevantes para serem explorados no projeto?

10. Como o projeto promoverá consciência sociopolítica? Quais melhorias o desenvolvimento do projeto pode trazer à turma/escola/ comunidade?

11. Como essas noções/ problemas/ temas dizem respeito a diferentes disciplinas escolares? Como artes, química, matemática ou filosofia, por exemplo, relacionam-se a esse tópico?

12. Há projetos sobre tópicos semelhantes desenvolvidos por outras professoras e estudantes? Como o trabalho foi feito? Que tipo de desafios enfrentaram? Quais soluções encontraram?

13. Que atividade pode ser implementada em sua turma? Como seria essa atividade e qual seria o seu objetivo?

Fonte: Adaptado de Scherer et al. (2014, p. 42)

Ao longo do projeto, o programa deverá ser submetido a discussões, negociações, avaliações e (re)construções (SCHERER et al., 2014, p. 30), tendo em vista que desejamos evitar a construção de um currículo que subordine a subjetividade do estudante e o desenvolvimento de habilidades para interpretar a vida contemporânea "à aprendizagem de alguns conteúdos, apresentados como entidades objetivas, estáveis, sem história e descontextualizadas" (HERNÁNDEZ, 1998, p. 19). Nesse sentido, o desenvolvimento conjunto de conhecimento da interrelação entre forma, conteúdo e função da linguagem em um dado contexto depende de atenção associada entre conteúdo da disciplina e as formas da língua em que esse conteúdo é mobilizado (LYSTER, 2018, p. 9).

Em relação aos documentos oficiais para o ensino de ILA, oferecemos algumas questões norteadoras para o cotejo entre as condições da comunidade escolar (Quadro 1) e os conteúdos curriculares (Quadro 2).

Quadro 2: Perguntas para investigação do currículo de ILA

1. Que currículo é projetado pela administração escolar, municipal, estadual e federal para as suas aulas de ILA?

2. Que habilidades e competências devem ser exploradas/estimuladas?

3. Que conteúdos linguísticos de ILA o currículo enumera?

4. Que dificuldades seus estudantes apresentam? 
5. Que discursos, noções, gêneros, registros, atos de fala e elementos léxico-gramaticais devem ser explorados com sua turma de ILA, relacionados ao tópico do projeto?

6. Como você pode conectar todos esses níveis de linguagem?

7. Que gêneros e registros podem dar melhor visibilidade para esses discursos?

8. Que atos de fala são frequentemente realizados nas situações em que esses registros funcionam?

9. Que elementos léxico-gramaticais devem ser postos em uso para realizar esses atos de fala, nesses registros? Como esses elementos léxico-gramaticais podem ser relacionados aos discursos e tópicos que a turma deseja abordar?

Fonte: Traduzido de Scherer et al. (2014, p. 97-98)

A partir desse levantamento sobre dados contextuais e currículo é possível dar início à escrita propriamente dita de um projeto de ensino.

\section{Produção do projeto de ensino}

O Quadro 3 oferece uma sugestão de organização textual, na qual os dados da escola e do projeto (seu tema, objetivos, metodologia e resultados, por exemplo) são inseridos para melhor visualização.

Quadro 3: Dados relevantes para elaboração de projeto interdisciplinar de ILA

\begin{tabular}{|c|c|c|}
\hline DADOS & TÓPICOS SUGERIDOS & $\begin{array}{l}\text { DADOS DA SUA } \\
\text { ESCOLA }\end{array}$ \\
\hline Escola & $\begin{array}{ll} & \text { Escola Federal... } \\
\text { - } & \text { Escola Estadual... } \\
\text { - } & \text { Escola Municipal... } \\
\text { - } & \text { Escola ... }\end{array}$ & \\
\hline Tema & $\begin{array}{l}\text { - ..é a noção/tema/problema que parece adequado para o desenvolvim- } \\
\text { ento de um projeto de ensino sob o ponto de vista de meus estudantes de } \\
\text { ILA. Também podemos explorar essa noção/tema/problema em nossa } \\
\text { aula de ILA quando ensinamos e aprendemos sobre... }\end{array}$ & \\
\hline Justificativa & $\begin{array}{l}\text { - O projeto foi motivado por ... } \\
\text { - } \quad \text { O projeto é relevante porque... } \\
\text { - A noção/tema/problema a ser explorado está relacionada/o ao nosso } \\
\text { currículo da seguinte forma... }\end{array}$ & \\
\hline Princípios & $\begin{array}{l}\text { - Situação diagnóstica: Nos últimos dois anos, a escola tem sido... } \\
\text { Construção colaborativa do conhecimento: todos (assistentes educa- } \\
\text { cionais, professoras, diretora, pais e mães etc.) na comunidade escolar } \\
\text { podem oferecer informações e ajudar a completar o projeto } \\
\text { - O papel dos estudantes como aprendizes ativos e pesquisadores de sua } \\
\text { própria realidade: Os estudantes são/foram capazes de... } \\
\text { O papel das professoras como educadoras, mediadoras e aprendizes: a } \\
\text { professora sugeriu que os estudantes.../solicitou aos estudantes que... } \\
\text { Interdisciplinaridade: o tópico/tema/problema está relacionado a artes, } \\
\text { química, matemática ou filosofia da seguinte forma: ... } \\
\text { Consciência sociopolítica: O projeto pode suscitar consciência política } \\
\text { da seguinte forma: .../ O projeto pode gerar transformação social da } \\
\text { realidade do próprio estudante da seguinte forma: ... }\end{array}$ & \\
\hline
\end{tabular}




\begin{tabular}{|c|c|}
\hline Objetivo(s) & $\begin{array}{l}\text { - Trazer à consciência da comunidade escolar a importância/ a relevância/ } \\
\text { a contribuição/ o perigo/ os benefícios/ os riscos de... } \\
\text { - Mudar as atitudes da comunidade escolar com relação a... } \\
\text { - Outro objetivo expressado por um verbo que representa o que meus } \\
\text { estudantes e eu gostaríamos de alcançar. }\end{array}$ \\
\hline Participantes & $\begin{array}{l}\text { - Meus estudantes e eu. } \\
\text { - A comunidade escolar como um todo (pais e mães, funcionários, institu- } \\
\text { içoes, ...) } \\
\text { - Professoras de outras disciplinas em diferentes áreas do conhecimento e } \\
\text { estudantes de outros níveis de ensino. } \\
\text { - Outras instituições na comunidade. }\end{array}$ \\
\hline $\begin{array}{l}\text { Etapa e mo- } \\
\text { dalidade } \\
\text { de ensino }\end{array}$ & $\begin{array}{l}\text { - } \text { Pré-escola? } \\
\text { - Fundamental I? } \\
\text { - } \text { Fundamental II? } \\
\text { - Ensino Médio? } \\
\text { - Educação de Jovens e Adultos? } \\
\text { - Educação profissional e tecnológica? }\end{array}$ \\
\hline Metodologia & $\begin{array}{l}\text { - Procedimentos: ações que tornam possível alcançar o objetivo. } \\
\text { - Exploraremos o problema/tema/tópico escolhido em nossas aulas de } \\
\text { ILA da seguinte forma: } \\
\text { - Ensinaremos e aprenderemos os seguintes componentes do currículo de } \\
\text { ILA para desenvolver nosso projeto: } \\
\text { - Para alcançar nossos objetivos neste projeto, iremos: } \\
\text { • gravar os sons de... } \\
\text { • filmar/tirar fotografias de ... } \\
\text { • submeter um questionário } \\
\text { • entrevistar... } \\
\text { • observar...para ...; } \\
\text { • desenhar e produzir um instrumento... } \\
\text { • promover um evento... } \\
\text { Materiais: recursos utilizados nos procedimentos, como celulares, } \\
\text { câmeras, projetores multimídia (datashow), ferramentas para..., com- } \\
\text { putadores, grafite, materiais reciclados, pintura, tinta, canetas/lápis/ } \\
\text { pincéis, diferentes tipos de papel, materiais de plástico, jornais, revistas } \\
\text { etc. }\end{array}$ \\
\hline $\begin{array}{l}\text { Avaliação/ } \\
\text { Resultados }\end{array}$ & $\begin{array}{l}\text { - Os resultados foram.... Os resultados mostram que... } \\
\text { - Ao elaborar e implementar o projeto, percebemos/ aprendemos que... } \\
\text { isso afetou a comunidade escolar da seguinte forma... } \\
\text { - Como resultado, nós... Não era o que esperávamos porque... O contexto/ } \\
\text { ambiente escolar mudou/não mudou em relação a ... }\end{array}$ \\
\hline
\end{tabular}

Fonte: Traduzido de Scherer et al. (2014, p. 101-102)

Uma vez que o contexto de ensino é planificado, pode-se definir os conteúdos programáticos a serem abordados naquele período escolar. Essa fase de implementação do projeto de ensino envolve: 1) estabelecer os objetivos do projeto (discursos que desejamos explorar); 2) elencar o(s) gênero(s) discursivo(s) no(s) qual(is) a turma deseja se engajar para atingir os propósitos comunicativos estabelecidos nos objetivos; e 3) delimitar os conteúdos léxico-gramaticais exigidos/ mobilizados pelos gêneros discursivos. 
Tal proposta é útil para ensinar conteúdos curriculares de ILA ou de qualquer disciplina. A ideia geral é fazer algo, usando a expressão linguística para fazê-lo em um contexto de aprendizagem onde o objetivo é ambicioso: mais do que aprender o código da língua em si, o objetivo é aprender a realizar algo no mundo concreto, usando ILA (EYJÓLFSDÓTTIR, 2011; JUAN-GARAU; SALAZAR-NOGUERA, 2015).

No caso de a comunidade escolar identificar a necessidade de debater princípios sustentáveis concernentes ao discurso ecológico, por exemplo, as noções de conservação ambiental, consumo, embalagens, recolhimento de lixo etc. serão consideradas. Apresentamos um plano de ensino de ILA a partir da PEPT, envolvendo o tópico Ecologia (Discurso Verde) no Quadro 4. O plano é organizado em planos comunicativos a partir do mais geral (discurso) ao mais específico (lista de conteúdos léxico-gramaticais tradicionalmente encontrados no currículo).

Quadro 4: Projeto sobre ecologia

\begin{tabular}{|c|c|c|c|c|c|}
\hline Discurso & Noções & Gêneros & Registros & Atos de fala & $\begin{array}{l}\text { Lexicogramática } \\
\text { Grafologia } \\
\text { Fonologia }\end{array}$ \\
\hline $\begin{array}{l}\text { Discurso } \\
\text { Verde }\end{array}$ & $\begin{array}{l}\text { - Primeiros } \\
\text { ambientalistas } \\
\text { - Prática } \\
\text { ecológica } \\
\text { - ONG's } \\
\text { - Sociedade } \\
\text { auto- } \\
\text { sustentável } \\
\text { - Sociedade } \\
\text { do } \\
\text { conhecimento } \\
\text {-Lixo seletivo } \\
\text {-Manejo dos } \\
\text { mananciais, } \\
\text { etc... }\end{array}$ & $\begin{array}{l}\text {-Apresenta- } \\
\text { ção oral } \\
\text {-Debate } \\
\text { regrado } \\
\text {-Filme } \\
\text {-Folder } \\
\text {-Livro } \\
\text { didático } \\
\text {-Mural } \\
\text { informativo } \\
\text {-Notícia } \\
\text {-Panfleto } \\
\text {-Pôster } \\
\text {-Projeto } \\
\text {-Relatório } \\
\text {-Reportagem } \\
\text {-Romance } \\
\text {-Sinopse } \\
\text {-Vídeoclip, } \\
\text { etc... }\end{array}$ & $\begin{array}{l}\text { - Carta Capital, } \\
\text { Superinteressante } \\
\text { CH, BBC news } \\
\text { Online } \\
\text { - National } \\
\text { Geographic, } \\
\text { Folha de SP } \\
\text {-Não verás país } \\
\text { nenhum, I. de } \\
\text { Loyola } \\
\text { Brandão, } 1981 \\
\text {-Lixo, } \\
\text { extraordinário, } \\
\text { Lucy Walker, } \\
\text { 2009, } \\
\text { •Panfleto de } \\
\text { campanha de } \\
\text { saúde } \\
\text { •Videoclip } \\
\text { Youtube, MTV } \\
\text { etc... }\end{array}$ & $\begin{array}{l}\text {-Acusar, } \\
\text {-Argumentar } \\
\text {-Avaliar } \\
\text { - Classificar } \\
\text { - Defender } \\
\text { - Definir } \\
\text { - Descrever } \\
\text { - Expor } \\
\text { - Identificar } \\
\text {-Informar } \\
\text { - Listar } \\
\text { - Narrar } \\
\text { - Ordenar } \\
\text {-Pedir } \\
\text {-Perguntar } \\
\text { - etc... }\end{array}$ & $\begin{array}{l}\text {-Transitividade de } \\
\text { Orações Materiais, } \\
\text { Verbais, Mentais, } \\
\text { etc... } \\
\text {-Tempo verbal: } \\
\text { Presente x Passado, } \\
\text { etc... } \\
\text {-Modo: Indicativo, } \\
\text { Imperativo, } \\
\text { Subjuntivo } \\
\text {-Índices de Coesão } \\
\text { lógica e temporal } \\
\text {-Índices de } \\
\text { Avaliação: Modali- } \\
\text { dade (Modalização, } \\
\text { Modulação) } \\
\text {-Índices de } \\
\text { Intertextualidade } \\
\text { (Citação e Relato, } \\
\text { Negação, Metáfora, } \\
\text { etc...) }\end{array}$ \\
\hline
\end{tabular}

Fonte: Motta-Roth (2011)

A turma pode se interessar por gêneros discursivos relativos a filmes de ação, vídeos de divulgação de música, notícias de popularização da ciência, letras de música ou podcasts, por exemplo. Qualquer um desses gêneros se realiza em texto que se desenvolve em sequências de atos de fala. Por exemplo, a notícia de popu- 
larização da ciência inicia por identificar uma nova pesquisa, expor os procedimentos da pesquisa, avaliar a descoberta e indicar a relevância desta para o dia a dia das pessoas. Esses atos de fala são realizados por meio da mobilização de itens léxico-gramaticais:

1. o ato de fala de identificar demanda o uso do verbo to be no presente, "Ecology is a very important topic";

2. o ato de expor demanda o uso de conetivos lógico-temporais, "Nowadays researchers explore new possibilities for the use of recycled plastic",

3. o ato de avaliar mobiliza índices de modalidade como should, em "Because we are interested in preservation, we should pay attention to how science can contribute to the future of our planet".

Uma vez organizados os vários planos comunicativos, podemos passar para as primeiras atividades do projeto. Uma parte inicial importante é dar visibilidade à turma, por meio de apresentações orais e escritas em ILA que podem ser disponibilizadas online ou no mural da classe ou da escola. Por exemplo, apresentações integrantes do discurso de identidade podem explorar noções concernentes a relações familiares e sociais, preferências e características profissionais e pessoais. Essas noções, por sua vez, podem ser organizadas por meio de diferentes gêneros discursivos, como perfil ou biodata, em registros específicos, como o perfil da turma em uma rede social como o Facebook e a biodata da professora de ILA na página da escola. Esses registros são caracterizados por atos de fala que realizam as ações discursivas de apresentar-se pessoal e profissionalmente, descrever a foto do perfil na rede social, "marcar" alguém em uma foto publicada, identificar/descrever a si e os outros e listar preferências. No plano comunicativo mais específico, o da léxico-gramática (grafologia e fonologia), exploram-se os elementos que realizam esses atos de fala, como pronomes pessoais, possessivos e demonstrativos, processos relacionais, o verbo to be, profissões, adjetivos e simple past (Quadro 5). 
Quadro 5: Sugestão de tabela de conteúdos para o tema "identidade" em uma aula de ILA

\begin{tabular}{|c|c|c|c|c|c|}
\hline \multicolumn{6}{|c|}{ TABLE OF CONTENTS } \\
\hline Discourse & Notions & Genre & Register & Speech acts & $\begin{array}{l}\text { Lexigrammar } \\
\text { Graphology } \\
\text { Fonology }\end{array}$ \\
\hline Self-identity & $\begin{array}{l}\text { Personal and } \\
\text { professional traits } \\
\text { Family and social } \\
\text { Relationships } \\
\text { Likes and dislikes } \\
\text { Hobbies } \\
\text { Age } \\
\text { Beliefs } \\
\text { Daily routine }\end{array}$ & $\begin{array}{l}\text { Biodata } \\
\text { Survey } \\
\text { Profile } \\
\text { Oral introduction } \\
\text { Picture }\end{array}$ & $\begin{array}{l}\text { Famous person biodata } \\
\text { English teacher biodata } \\
\text { Facebook profile }\end{array}$ & $\begin{array}{l}\text { Introducing yourself } \\
\text { personally and } \\
\text { professionally } \\
\text { Spelling names and e-mail } \\
\text { addresses } \\
\text { Tagging people in a picture } \\
\text { Listing likes and dislikes } \\
\text { Asking/answering questions } \\
\text { Identifying/describing } \\
\text { myself and others }\end{array}$ & $\begin{array}{l}\text { Personal Pronouns } \\
\text { Alphabet } \\
\text { Relational Process } \\
\text { Verb to be } \\
\text { Numbers } \\
\text { Countries and nationalities } \\
\text { Present Continuous } \\
\text { Sports } \\
\text { Greetings } \\
\text { Present Perfect Continuous } \\
\text { There to be } \\
\text { Demonstrative Pronouns } \\
\text { Adjectives } \\
\text { Nouns } \\
\text { Related-colors vocabulary } \\
\text { Prepositions of place and } \\
\text { direction } \\
\text { Adverbs } \\
\text { Related-clothes vocabulary }\end{array}$ \\
\hline
\end{tabular}

Fonte: Scherer et al. (2014, p. 53)

Como fechamento do trabalho a partir da PEPT e Ensino com base em conteúdo, sugerimos que professora e estudantes promovam uma (auto)avaliação qualitativa. Conforme explicamos na próxima seção, esse processo enfoca o que os participantes aprenderam/ensinaram sobre si e sobre o mundo, como esse processo ocorreu e em que medida contribuíram para alterar positivamente sua comunidade.

\section{Avaliação}

Em nossa concepção, uma avaliação qualitativa deve se constituir por mais uma instância de aprendizagem, que vise à melhoria do ensino e da aprendizagem, particularmente ao desenvolvimento das capacidades de estudantes de usar e analisar a linguagem em contextos relevantes.

Ressaltamos a importância do desenho de uma avaliação contínua e formativa, relevante para cada contexto específico, focada nas necessidades, aprendizagem e competências que reflitam uma prática centrada na aprendizagem pessoal e local de estudantes (KELL, 1996, p. 255), não apenas em termos dos conteúdos ensinados, mas também em termos do processo de aprendizagem individual (KUMARAVADIVELU, 2006, p. 157).

Cizek (2010, p. 6) usa o termo "avaliação formativa" conforme definido por Bloom, Hastings e Madaus:

Avaliação formativa é, para nós, o uso de avaliação sistemática no processo de construção do currículo, ensino e aprendizagem para fins de melhorar qualquer um desses três processos.... Isso significa que (...) devemos 
nos empenhar em desenvolver os tipos de evidência que serão mais úteis no processo, buscar o método mais útil para reportar a evidência, e procurar maneiras de reduzir o efeito negativo associado à avaliação - talvez reduzindo os aspectos condenatórios da avaliação ou, ao menos, fazendo com que os participantes da avaliação formativa (professoras, estudantes, elaboradoras de currículo) se responsabilizem por fazer essas críticas. (1971, p. 118, tradução nossa, grifo nosso).

Da perspectiva de uma avaliação (trans)formativa, também é importante que nós, professoras, assumamos uma atitude proativa na avaliação de nossa prática, para alcançar uma "evolução epistemológica" por meio de questionamentos como: "Em que medida minhas estratégias e métodos de ensino foram eficazes?" e "O que eu poderia mudar na próxima vez em que eu ensinar este [conteúdo]?" (BROOKHART, 2010, p. 292). Exemplo dessa atitude reflexiva se encontra na chamada "Avaliação Horizontal", processo dialógico, usado na supervisão de professoras pré-serviço que encoraja professoras supervisoras e estagiárias a questionar e revisar crenças, noções e objetivos que guiam sua prática pedagógica e que também auxilia a investigar novas maneiras de conectar teoria e prática (GITLIN, 1981, p. 48-49). No caso da elaboração de objetivos de uma unidade didática de ILA, as professoras podem discutir por que motivos aqueles objetivos são importantes e quem será beneficiado por eles. Verbalizar as motivações particulares no processo de preparação de aula "ajuda a professora a ser mais clara sobre as afirmações e valores implícitos em sua explicação” (GITLIN, 1987, p. 22). Assim, na avaliação horizontal, "professoras analisam colaborativamente a relação entre as intenções de seu ensino e suas práticas" (BAUMANN; BISPLINGHOFF; ALLEN, 2005, p. 127) de modo a subverter a verticalidade das relações tradicionalmente praticada em situações de avaliação, em que o par supostamente mais competente ou experiente julga se o par supostamente menos competente ou experiente atingiu níveis predeterminados de competências (GITLIN, 1981, p. 46). A avaliação horizontal, alternativamente, é um processo em que a compreensão da própria prática pedagógica por meio da interação dialógica entre pares é o objetivo da avaliação (GITLIN, 1987, p. 17).

\section{A título de conclusão}

$\mathrm{Na}$ adoção da PEPT e do Ensino com base em conteúdo, a referência norteadora consiste nas características de desconstrução e reinvenção na era da pedagogia pós-método do século XXI. Essa pedagogia comporta três parâmetros pedagógicos interrelacionados: 1) situacionalidade (incentiva a promoção de um conhecimento pedagógico situado e sensível ao grupo particular de professoras e estudantes em um contexto institucional específico); 2) praticalidade (supera a dicotomia teoria versus prática e combate consumo acrítico de teorias, instigando professoras a construírem suas próprias soluções/teorias informadas pela prática); e 3) possibilidade (dispõe da consciência sociopolítica da comunidade escolar para fortalecer as identidades individuais e promover a transformação social por meio da educação linguística) (KUMARAVADIVELU, 2001; 2003; 2006). 
Nessa perspectiva, as professoras buscam, a partir das necessidades de estudantes e desafios encontrados em cada sala de aula, lançar mão das diferentes teorias, refletir criticamente sobre elas e criar sua própria metodologia:

[...] alicerçada em bases socioculturais [que] propõe a construção do conhecimento por meio da análise global e local do contexto, possibilitando o diálogo entre participantes (estudantes, professoras e comunidade). Nesses termos, o processo de ensino e aprendizagem de línguas - e aqui mais especificamente o ILA - oportuniza situações para que 1) o estudante se coloque como protagonista de sua própria aprendizagem e 2) o/a professor/a seja capaz de constantemente repensar a sua prática. Sendo assim, ambos os papéis, de estudante e professora, envolvem o senso de autonomia, em que o estudante se torna protagonista, capaz de aprender a aprender, de monitorar seu processo de aprendizagem, e o/a professora como participante do processo, torna-se capaz de analisar e avaliar suas ações, propondo mudanças e reavaliando os efeitos dessas mudanças (KUMARAVADIVELU, 2006 apud SCHERER et al., 2014, p. 25).

Neste trabalho, propomos três etapas para a implementação de um projeto de ensino, relacionadas aos três parâmetros pedagógicos propostos na pedagogia pós -método: 1) Sondagem e avaliação do contexto (situacionalidade); 2) Produção do projeto de ensino (praticalidade); e 3) Avaliação (possibilidade). A sondagem por professora e estudantes promove a escolha da problemática a ser abordada, considerando o contexto local e a experiência de vida dos estudantes em sua comunidade. A produção do projeto encoraja professoras e estudantes a assumirem o papel de autores e de pesquisadores para criar diferentes possibilidades de resolução dos problemas encontrados. Assim, a turma tem a possibilidade de mobilizar colaborativamente o conhecimento escolar para promover melhorias na comunidade. Por fim, na etapa de avaliação (possibilidade), estudantes e professora avaliam em que medida os objetivos foram atingidos e como a turma e a comunidade escolar receberam o projeto e seus resultados (SCHERER et al., 2014, p. 91-92). Por exemplo, a turma avalia conjuntamente em que medida foi bem-sucedida na melhoria das condições de segurança da escola e de seu entorno por meio de campanha/abaixo-assinado para reivindicar soluções para o problema. Evidentemente, em uma proposta pós-método, a avaliação é contínua e convida à (re)elaboração constante de modificações necessárias à medida que o projeto se desenvolve (revendo a situacionalidade do projeto). Alguns exemplos de projetos autorais desenvolvidos em contextos escolares específicos podem ser vistos em Back e Stein (2016); Ernzen e Lameira (2016); Prado e Lange (2011); Timboni e Wink (2016); Vial e Silva (2014).

Para finalizar, gostaríamos de chamar a atenção para alguns dos desafios e vantagens detectados por nós no processo de apropriação do conceito de gênero discursivo na aula de ILA, considerando a prática pedagógica e as discussões no campo da LA:

- Desafiar a estrutura do modelo escolar que frequentemente relega a aula de ILA à última prioridade; 
- Estudar, compreender e incorporar o conceito de gênero discursivo (conforme recentemente recontextualizado nas Ciências da Linguagem) à teoria pessoal de professoras de ILA uma vez que a adoção desse conceito como central ao desenvolvimento dos projetos implica visões de linguagem, ensino e aprendizagem (SCHERER et al., 2014);

- Vincular teoria e prática, revendo a teoria a partir da prática e a prática a partir da teoria;

- Construir uma aula de ILA como um laboratório em que descobrimos contextos relevantes de língua em uso como uma prática social;

- Vencer a falta de organização do tempo de forma realista para dar conta de um ensino teoricamente informado;

- Enfim, tomar o conceito de gênero discursivo no ensino de ILA como textualização da experiência humana demanda descolar do pensamento atomístico tradicional acerca da linguagem em direção a uma pedagogia pós-método que é situada, não opõe teoria e prática e que conclama a uma educação linguística com consciência sociopolítica da formação de identidade e voltada à transformação social.

Sugerimos que nossa sala de aula de ILA contemple a construção de conhecimento por meio da investigação de estruturas sociais, políticas, culturais e históricas mais amplas a fim de dar a professoras e estudantes condições de desnaturalizar discursos postos e, a partir disso, construir para si e suas comunidades um bom lugar no mundo (KUMARAVADIVELU, 2006 apud SCHERER et al., 2014, p. 30).

Notas

1. Este artigo foi confeccionado com apoio de bolsa CNPq PQ No. 308979/2017-6 para a primeira autora e CAPES para a segunda autora.

2. Neste trabalho, sempre que fizermos referência à profissão, utilizaremos o termo professoras, pois as autoras são do gênero feminino e entendemos que a maioria deve denotar o grupo.

3. Hernández (2014, p. 65) indica a atualização do termo "Pedagogia de Projetos" anteriormente usado: "Faz tempo que não utilizamos estas denominações ["pedagogia de projetos", "educação por projetos" ou "projetos de trabalho"], pois não representam o que fazemos nas aulas e distorcem nossa visão da educação. Falamos da perspectiva educativa de projetos de trabalho (PEPT) que é uma visão a respeito das relações pedagógicas e do aprendizado por meio do diálogo e da indagação".

4. Optamos pelo termo "língua adicional" (JUDD; TAN; WALBERG, 2001) por entendermos que a língua não é "estrangeira" ou "distante", mas sim uma "parte dos recursos necessários para a cidadania contemporânea”, oportunizando a ampliação de espaços de participação tanto na sala de aula quanto na vida cotidiana (SCHLATTER; GARCEZ, 2009, p. 128, 132). 
5. A interdisciplinaridade, em contextos de aprendizagem, “[...] pode ser pensada como um processo de organização dos conteúdos, em que haja a integração de várias disciplinas, como geografia, história, língua portuguesa. [...] Uma aula de biologia, na qual os estudantes analisam rótulos de produtos em busca de componentes químicos, pode promover um trabalho interdisciplinar com a matemática (cálculo do consumo de nutrientes de acordo com a tabela de informações nutricionais do produto), línguas (alguns alimentos são apresentados em inglês e em português) e artes (análise estética da embalagem)" (SCHERER et al., 2014, p. 22).

6. Projeto coordenado pela primeira autora deste artigo, em conjunto com as professoras Luciane Kirchhof Ticks, Roséli Nascimento e Susana Cristina dos Reis, do LABLER-Laboratório de Pesquisa e Ensino de Leitura e Redação/UFSM, entre 2013 e 2014, com financiamento do Programa Mais Educação, da Secretaria de Educação Básica, do Ministério da Educação.

\section{Referências}

BACK, R. M. M.; STEIN, F. Planejando um projeto de aprendizagem: quando todos podem participar, todos podem aprender. Revista Bem Legal, Porto Alegre, v. 6, n. 2, p. 305-316, 2016. Disponível em: http://www.ufrgs.br/revistabemlegal/ edicoes-anteriores/Vol\%2C6\%20n.2/34. Acesso em: 28 jun. 2021.

BANAJI, S.; BUCKINGHAM, D. The civic web: young people, the internet and civic participation. Cambridge, Massachusetts/London, England: The MIT Press, 2013.

BARBOSA, M. C. S. Por que voltamos a falar e a trabalhar com a pedagogia de projetos? Projeto - Revista de Educação, v. 3, n. 4, p. 8-13, 2004.

BAUMANN, J. F.; BISPLINGHOFF, B. S.; ALLEN, J. Methodology in teacher research three cases. In: FLOOD, J.; HEATH, S. B.; LAPP, D. (Eds.). Handbook of research on teaching literacy through the communicative and visual arts. Mahwah, NJ/ London: Lawrence Erlbaum, 2005, p. 121-143.

BAZERMAN, C. Gêneros textuais, tipificação e interação. Tradução Judith Chambliss Hoffnagel. Organização Ângela Paiva Dionísio e Judith Chambliss Hoffnagel. São Paulo: Cortez, 2009.

BLOOM, B.; HASTINGS, J. T.; MADAUS, G. Handbook on formative and sumative evaluation of student learning. New York: McGraw-Hill Book Company, 1971.

BRASIL. Secretaria de Educação Fundamental. Parâmetros curriculares nacionais: terceiro e quarto ciclos do ensino fundamental: língua estrangeira. Brasília: MEC/SEF, 1998. Disponível em: http://portal.mec.gov.br/seb/arquivos/pdf/pcn_ estrangeira.pdf. Acesso em: 29 jun. 2021.

BRONCKART, J.-P. Atividade de linguagem, textos e discursos: por um interacionismo sócio-discursivo. São Paulo: EDUC, 1999.

BROOKHART, S. M. Mixing it up: combining sources of classroom achievement information for formative and summative purposes. In: ANDRADE, H. L.; CIZEK, G. J. (Eds.). Handbook of formative assessment. New York/London: Routledge, 2010, p. 279-296.

CALDAS-COULTHARD, C. R. Cross-cultural representation of 'otherness' in media discourse. In: WEISS, G.; WODAK, R. (Eds.). Critical discourse analysis: theory and interdisciplinarity. Hampshire, UK/New York, USA: Palgrave MacMillan, 2003, p. 272-296.

CIZEK, G. J. An introduction to formative assessment: history, characteristics, and challenges. In: ANDRADE, H. L.; CIZEK, G. J. (Eds.). Handbook of formative assessment. New York/London: Routledge, 2010, p. 3-17. 
COTS, J. M. Teaching 'with an attitude': critical discourse analysis in EFL teaching. ELT Journal, v. 60, n. 4, p. 336-345, 2006.

DEWEY, J. Vida e educação. São Paulo: Melhoramentos, 1967.

DEWEY, J. How we think: a restatement of the relation of reflective thinking to the educative process. Lexington, MA: D.C. Heath and Company, 1933.

ERNZEN, R. B.; LAMEIRA, V. M. Uma entrevista importante em inglês: e agora? Revista Bem Legal, Porto Alegre, v. 6, n. 2, p. 21-31, 2016. Disponível em: http://www.ufrgs.br/revistabemlegal/edicoes-anteriores/Vol\%2C6\%20n.2/5. Acesso em: 28 jun. 2021.

EYJÓLFSDÓTTIR, T. Content-based instruction: a closer look at CBI in Iceland. Manuscrito. Menntavísindasvið Háskóla Íslands, 2011. Disponível em: https:// skemman.is/bitstream/1946/9704/3/Lokaritger\%c3\%b0\%20pdf.pdf. Acesso em: 29 jun. 2021.

FAIRCLOUGH, N. Language and power. New York: Longman, 1989.

FAIRCLOUGH, N. Discourse and social change. London: Polity Press, 1992.

FAIRCLOUGH, N. Analysing discourse: textual analysis for social research. London: Routledge, 2003.

FREIRE, P. A importância do ato de ler - em três artigos que se complementam. 39. ed. São Paulo: Cortez, [1982] 2000.

FREIRE, P. Pedagogia do oprimido. 50. ed. rev. e atual. Rio de Janeiro: Paz e Terra, $1974 / 2011$.

GEE, J. P. An introduction to discourse analysis. New York: Routledge, 1999.

GIROUX, H. A. Os professores como intelectuais: rumo a uma pedagogia crítica da aprendizagem. Porto Alegre: Artes Médicas, 1997.

GITLIN, A. Horizontal evaluation: an approach to student teacher supervision. Journal of Teacher Education, v. XXXII, n. 5, p. 47-50, 1981.

GITLIN, A. A dialogical approach to understanding: horizontal evaluation. Educational Theory, v. 37, n. 1, p. 17-27, 1987.

HALLIDAY, M. A. K.; HASAN, R. Language, context, and text: aspects of language in a social-semiotic perspective. Oxford: Oxford University Press, [1985] 1989.

HALLIDAY, M. A. K.; MARTIN, J. R. Writing science: literacy and discursive power. Pittsburgh: University of Pittsburgh Press, 1993.

HALLIDAY, M. A. K.; MATTHIESSEN, C. M. M. M. An introduction to functional grammar. 4. ed. London: Hodder Arnold, 2014.

HERNÁNDEZ, F. Transgressão e mudança na educação: os projetos de trabalho. Porto Alegre: Artmed, 1998.

HERNÁNDEZ, F. Os projetos de trabalho: um mapa para navegantes em marés de incertezas. Projeto - Revista de Educação, Porto Alegre, v. 3, n. 4, p. 2-7, 2001.

HERNÁNDEZ, F. Entrevista com o Professor Fernando Hernández. Revista Bem Legal, Porto Alegre, v. 4, n. 1, p. 65-72, 2014. Disponível em: http://www.ufrgs. br/revistabemlegal/edicoes-anteriores/no_1_2014/entrevista. Acesso em: 04 jun. 2021.

JUAN-GARAU, M.; SALAZAR-NOGUERA, J. (Eds.). Content-based language learning in multilingual educational environments. Heidelberg/New York/ Dordrecht/London: Springer, 2015. 
JUDD, E. L.; TAN, L.; WALBERG, H. J. Teaching additional languages. International Academy of Education, 2001.

KELL, C. Literacy practices in an informal settlement in the Cape Peninsula. In: PRINSLOO, M.; BREIER, M. (Eds.). The social uses of literacy: theory and practice in contemporary South Africa. Cape Town/Amsterdam: Sached Books/ John Benjamins Publishing Company, 1996.

KENNEY, T. Why the Nazi Regime Saw U.S. Jim Crow Laws as Inspiration for Its Own Racist Laws. Atlanta Black Star, 19 de dez. de 2016. Disponível em: https:// atlantablackstar.com/2016/12/19/why-the-nazi-regime-saw-u-s-jim-crow-lawsas-inspiration-for-its-own-racist-laws/. Acesso em: 30 nov. 2021.

KINCHELOE, J. L. Teachers as researchers: qualitative paths to empowerment. New York: Routledge Falmer, 2003.

KLEIMAN, A. B.; MORAES, S. E. Leitura e interdisciplinaridade: tecendo redes nos projetos da escola. Campinas, SP: Mercado de Letras, 2009.

KUMARAVADIVELU, B. Toward a postmethod pedagogy. TESOL Quarterly, v. 35, n. 4, p. 537-560, 2001.

KUMARAVADIVELU, B. Beyond methods: macrostrategies for language teaching. New Haven, CT: Yale University Press, 2003.

KUMARAVADIVELU, B. Understanding language teaching: from method to postmethod. New Jersey: Lawrence Erlbaum Associates, Inc., Publishers, 2006.

LEFFA, V. L; IRALA, V. B. Uma espiadinha na sala de aula: ensinando línguas adicionais no Brasil. Pelotas: EDUCAT, 2014. Disponível em: https://www.leffa. pro.br/textos/trabalhos/livro_espiadinha.pdf. Acesso em: 02 dez. 2021.

LYSTER, R. Content-based language teaching. New York/Oxon: Routledge, 2018.

MARTIN, J. E. English text: system and structure. Philadelphia/Amsterdam: John Benjamins, 1992.

MARTIN, J. E. Mentoring semogenesis: 'genre based' literacy pedagogy. In: CHRISTIE, F. (Ed.). Pedagogy and shaping of consciousness: linguistics and social processes. London: Continuum, 1999, p. 123-155.

McCARTHY, M.; CARTER, R. Language as discourse: perspectives for language teaching. London: Longman, 1994.

MENDONÇA, M. R. S. Projetos temáticos: integrando leitura, produção de texto e análise linguística na formação para a cidadania. Construir Notícias, v. 21, p. 49-53, 2005. Disponível em: http://www.construirnoticias.com.br/projetostematicos/. Acesso em 29 jun. 2021.

MENEZES, I. R.; CRUZ, A. R. S. da. Método de projeto x projeto de trabalho: entre novas e velhas ideias. Sitientibus, Feira de Santana, n. 36, p. 109-125, jan./jun. 2007.

MEURER, J. L.; BONINI, A.; MOTTA-ROTH, D. (Orgs.). Gêneros: teorias, métodos e debates. São Paulo: Parábola Editorial, 2005.

MOTTA-ROTH, D. O ensino de produção textual com base em atividades sociais e gêneros textuais. Linguagem em (Dis)Curso, v. 6, n. 3, 2006. Disponível em: https://portaldeperiodicos.unisul.br/index.php/Linguagem_Discurso/article/ view/347/368. Acesso em: 11 jan. 2022.

MOTTA-ROTH, D. Análise crítica de gêneros: contribuições para o ensino de linguagem. D.E.L.T.A., São Paulo, v. 24, n. 2, p. 341-383, 2008. Disponível em: http://www.scielo.br/pdf/delta/v24n2/v24n2a07.pdf. Acesso em: 11 jan. 2022. 
MOTTA-ROTH, D. Sistemas de gêneros e recontextualização da ciência na mídia eletrônica. Gragoatá (UFF), v. 28, p. 153-174, 2010. Disponível em: https:// periodicos.uff.br/gragoata/article/view/33099/19086. Acesso em: 11 jan. 2022.

MOTTA-ROTH, D. Gêneros discursivos: teoria e ensino. Minicurso ministrado no XX Instituto da ABRALIN, VII Congresso Internacional da ABRALIN, Associação Brasileira de Linguística - Universidade Federal do Paraná, Curitiba, PR. 2011. Disponível em: https://sites.google.com/site/abralincurtiba2011/ minicursos-disponiveis-no-xx-instituto. Acesso em: 11 jan. 2022.

MOTTA-ROTH, D.; LOVATO, C. Organização retórica do gênero notícia de popularização da ciência: um estudo comparativo entre português e inglês. Linguagem em (Dis)curso (Impresso), v. 09, p. 233-271, 2009. Disponível em: http://www.scielo.br/pdf/ld/v9n2/03. Acesso em: 11 jan. 2022.

PALLY, M. Sustained content-based teaching for academic skills development in ESL/EFL. ED 431 324. Educational Resources Information Center (ERIC), New York, 1999. Disponível em: http://files.eric.ed.gov/fulltext/ED431324.pdf. Acesso em: 29 jun. 2021.

PALLY, M. et al. What is learned in sustained-content writing classes along with writing?, v. 21, n.1, p. 90-115, 2002. Disponível em: https://wac.colostate.edu/ jbw/v21n1/pally.pdf. Acesso em: 29 jun. 2021.

PRADO, V. V.; LANGE, C. P. Yes we can! Uma prática de letramento na aula de inglês da EJA. Revista Bem Legal, Porto Alegre, v. 1, n. 1, p. 30-37, 2011. Disponível em: http://www.ufrgs.br/revistabemlegal/edicoes-anteriores/vol1n1-2011/1-7\%20 -\%20Yes\%20we\%20can-\%20-Vanessa\%20Viega\%20Prado\%20e\%20Catilcia\%20 Pass\%20Lange.pdf. Acesso em: 26 jun. 2021.

REIS, S. C. dos; GOMES, A. F. Podcasts para o ensino de língua inglesa: análise e prática de letramento digital. Calidoscópio, v. 12, n. 3, p. 367-379, 2014.

SCHLATTER, M. O ensino de leitura em língua estrangeira na escola: uma proposta de letramento. Calidoscópio, v. 7, n. 1, p. 11-23, 2009. Disponível em: http:// revistas.unisinos.br/index.php/calidoscopio/article/view/4851/2109. Acesso em: 02 dez. 2021.

SCHERER, A.; MOTTA-ROTH, D. Contribuições da análise crítica de gênero para a promoção de letramentos em inglês como língua adicional. In: TOLDO, C.; STURM, L. (Orgs.). Letramento: práticas de leitura e escrita. Campinas, SP: Pontes Editores, 2015, p. 79-106.

SCHERER, A. S. et al. Diretrizes curriculares para o ensino de inglês na escola: caderno de formação. Portal WebEnglish, Universidade Federal de Santa Maria/ SEB/MEC-UFSM, 2014. Disponível em: http://coral.ufsm.br/webenglish/static/ arquivo/142_diretrizes-curriculares-para-o-ensino-de-ingles-na-escola.pdf. Acesso em: 11 jan. 2022.

TIMBONI, K. A. da S.; WINK, C. O. A temática "estereótipos" na aula de português como língua adicional: a questão indígena na sala de aula. Revista Bem Legal, Porto Alegre, v. 6, n. 1, p. 88-97, 2016. Disponível em: http://www.ufrgs. br/revistabemlegal/edicoes-anteriores/vol6n12016/10. Acesso em: 28 jun. 2021.

VIAL, A. P. S.; SILVA, L. G. da. Copa do Mundo no Brasil e nas aulas de inglês. Revista Bem Legal, Porto Alegre, v. 4, n. 2, p. 79-89, 2014. Disponível em: http://www. ufrgs.br/revistabemlegal/edicoes-anteriores/no2-2014/copa-do-mundo-nobrasil-e-nas-aulas-de-ingles. Acesso em: 28 jun. 2021.

VOLOCHINOV, V. N. Marxismo e filosofia da linguagem. São Paulo: Editora Hucitec, [1929] 1995. 
VYGOTSKY, L. S. Pensamiento y palabra. In: VYGOTSKY, L. S. Obras escogidas: pensamiento y lenguaje. 2. ed. Primera Parte, Tomo II. Madri: A. Machado Libros. 2001, p. 287-348.

WOOD, D.; BRUNER, J. S.; ROSS, G. The role of tutoring in problem solving. Journal of Child Psychology and Psychiatry, v. 17, p. 89-100, 1976.

Recebido em: 30/06/2021 Aceito em: 29/11/2021 